\title{
Sonogram of Biliary Dilatation in Children
}

\author{
Hung-Chang Lee, Chuen-Bin Jiang, Wai-Tao Chan, Chun-Yan Yeung \\ Division of Pediatric Gastroenterology and Nutrition, \\ Department of Pediatrics, Mackay Memorial Hospital, Taipei \\ Taiwan
}

\section{Introduction}

The biliary trees descend from the canaliculi at the hepatocytes in the liver. Bile drains from this level into intrahepatic ducts, smaller ducts combine to form the segmental bile ducts which within the liver gradually enlarge and merge to the right and left hepatic ducts. The right and left hepatic ducts join together to form the common hepatic duct (CHD) at porta hepatis. The common bile duct (CBD) is formed by the junction of the cystic duct with the CHD. The CBD traverses through the head of the pancreas entering the duodenum through the Sphincter of Oddi at the Ampulla of Vater. Prior to draining into the duodenum, the CBD is joined by the pancreatic duct. A smaller accessory pancreatic duct and sphincter is usually present (but rarely visible by sonography ) from the dorsal pancreatic embryologic rotation. (Fig. 1)

\section{Scanning technique and normal findings of biliary tree}

A standard commercial purpose ultrasound machine can perform the typical biliary system study of children in routine examinations of the gallbladder and the bile ducts. Curvilinear abdominal probes with the frequency range of $3-5 \mathrm{MHz}$ are ideal for examination of the biliary tree, thus enabling the detection of the gallbladder and bile ducts from a wide range of body sizes (from obese children to small infants).

To perform the examination of the biliary tree sonography, the child is usually in the supine position. All children prepared for ideal ultrasound examination of the gallbladder and bile ducts should fast for at least 4-6 hours prior to the examination. Adequate fasting distends the gallbladder and bile ducts for optimal investigation of the lumen and the wall. Since the duodenum is in close proximity to both the gallbladder and the extrahepatic ducts, fasting also reduces the contents of the stomach and duodenum which very often obscure the common bile duct.

The gallbladder is a pear-shaped structure with thin white walls surrounding a black fluid lying in a fossa formed by the junction of the right and left main lobes of the liver. The most effective window to scan the gallbladder is to sweep the transducer over the right subcostal area. The maneuver starts with the probe in longitudinal orientation and the probe-indicator oriented toward the patient's head. By sweeping the probe, the gallbladder is identified and makes small adjustments to create the best long-axis view. After the long-axis is thoroughly examined, rotate the probe 90 degrees and demonstrate the short-axis view (Fig. 2). 


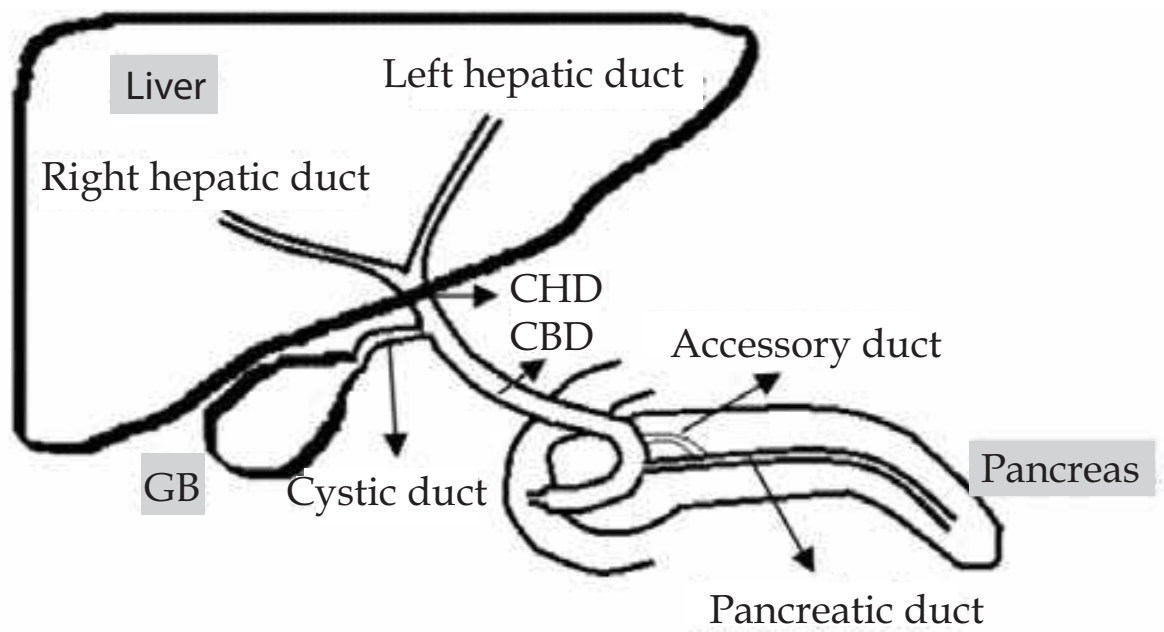

Fig. 1. The anatomy of the biliary tree. (GB: gallbladder, CHD: common hepatic duct, CBD: common bile duct)

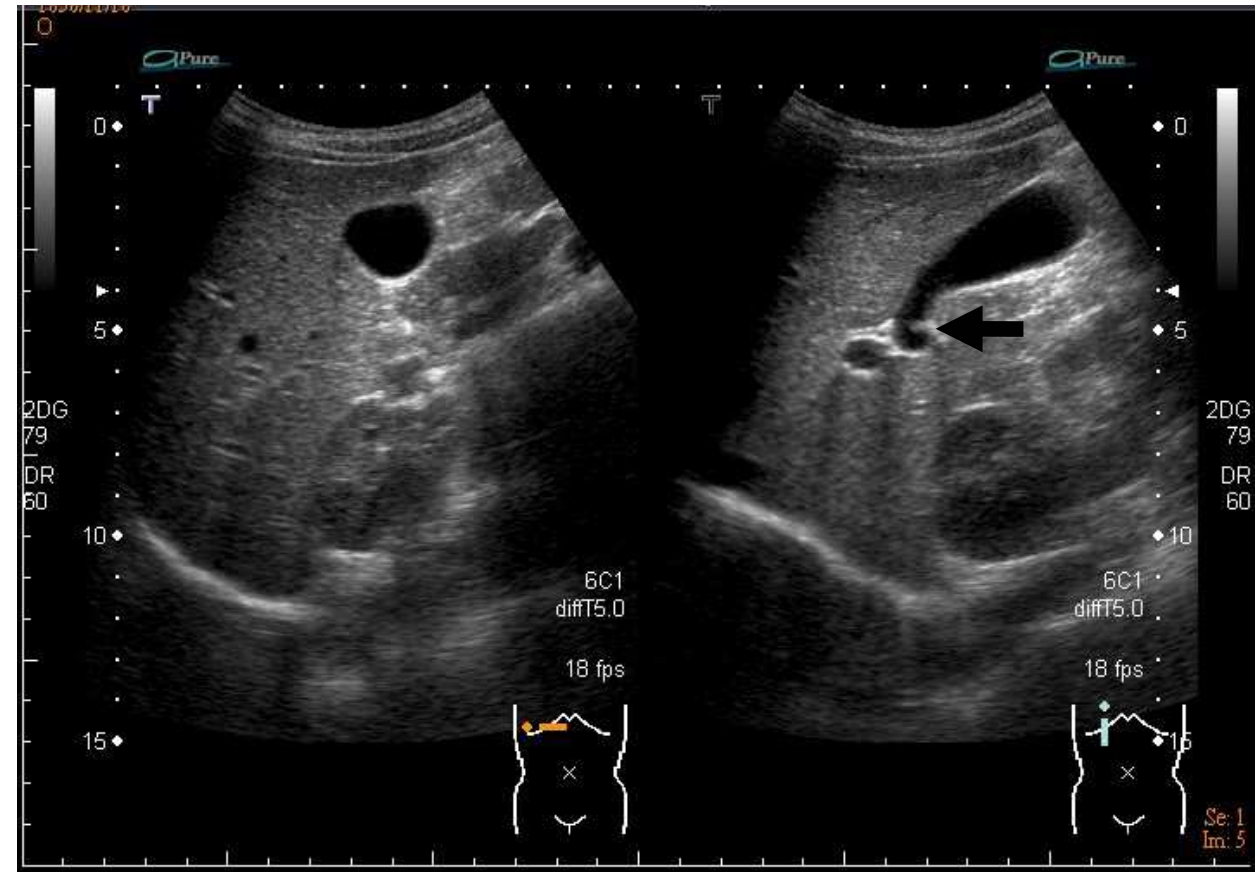

Fig. 2. Normal presentation of gallbladder. Left: the short-axis view. The gallbladder appears spherical. The narrowest portion of the wall is proper to measure the wall of gallbladder. Right: the long-axis view. The gallbladder will usually appear as a pear-shaped, hypoechoic structure with a hyperechoic wall. There is no acoustic shadowing posterior to the gallbladder. The wall folds one time upon itself may falsely present a septum (arrow) 
In the short-axis view, the gallbladder will appear spherical. The whole gallbladder should be demonstrated from the neck to the fundus. The normal length of gallbladder is 1.5 to 3.0 $\mathrm{cm}$ in neonates and young infants, and approximately $1 \mathrm{~cm}$ in normal width. In older children and adolescents, the gallbladder length is 3 to $8 \mathrm{~cm}$ and the width is less than 3.5 $\mathrm{cm} .{ }^{1}$ Sometimes the gallbladder wall may falsely present a septum because the wall folds one or several times upon itself. The size of normal and pathological gallbladder shows a great variability from a normal large to a small slender gallbladder. It depends on the fasting condition, the degree of the distention and the possible underlying disease. Similarly, the wall thickness is variable and depends on the same conditions. Evaluation from the short-axis view is the gold standard to measure the wall thickness of gallbladder and at its most narrow point is the best reliable place to measure the anterior wall. The normal wall of gallbladder is thin and hyperechoic with mild posterior enhancement. The upper limit of $w$ all thickness is $3 \mathrm{~mm}$ in the fasting state. ${ }^{2}$ The neck of the gallbladder joins the cystic duct and locates near the hilar region of the liver. Generally there is no acoustic shadowing posterior to the gallbladder.

The cystic duct is a folded tubular structure, and it joins the common hepatic duct to create the common bile duct. It lies posterior to the common bile duct in 95 percent and anterior to the common bile duct in 5 percent of individuals. ${ }^{3}$ The cystic duct in children is not routinely seen unless it is dilated. ${ }^{4}$ It is usually seen only the distal part of the duct near its insertion into the common bile duct.

The CBD is easily identified through its association with the portal vein. In the long axis view of the gallbladder, adjust the probe from the neck of the gallbladder to the porta hepatis and the portal vein will appear as a hypoechoic with echogenic walls. The CBD presents just anterior to the portal vein and three echogenic lines will be seen (Fig. 3). The first line closest to the probe will be the anterior wall of the common bile duct. The second line is the shared wall of the CBD and portal vein. Finally, the third line is the posterior wall of the portal vein. The differentiation between the CBD and portal vein can be easily done by color Doppler technique if there is confusion to distinguish. The portal vein will demonstrate flow and the CBD does not. The diameter of the common duct should be measured on the sagittal scan to confirm the presence or absence of ductal dilatation. Measurement of the caliper of CBD is usually done between the interior margin of the anterior and the posterior wall. The distal portion of the common duct is typically larger than the proximal portion. ${ }^{4}$ It is very difficult to follow the CBD once it passes posterior to the second portion of the duodenum.

\section{How dilated is dilated?}

Because ultrasonography is easy to perform and does not expose the patient to radiation or contrast agents, it is being used more often in children to diagnose disorders of the biliary tract and gallbladder. ${ }^{5-7}$ Measurement of the extrahepatic bile duct (CBD) is usually taken at the level where paralleled with the portal vein. The upper limit of normal for the CBD of infants and children has been estimated in several studies. Hernanz-Schulman et $\mathrm{al}^{1}$ reported an upper limit of $1.2 \mathrm{~mm}$ in infants $<3$ months old, less than $1.6 \mathrm{~mm}$ in infancy and less than $3 \mathrm{~mm}$ in childhood. Carroll et $\mathrm{al}^{8}$ stated that a normal common bile duct should not exceed $1 \mathrm{~mm}$ in infants $<3$ months old. E. Fitzpatrick et al ${ }^{9}$ stated that bile duct 
dilatation $<3 \mathrm{~mm}$ (non-fasting ultrasound) with neonatal cholestasis is unlikely to be of significance whereas $>4 \mathrm{~mm}$ is likely to be associated with choledochal malformation or need for intervention. Siegel 10 stated that the sonographic findings of a visible intrahepatic biliary duct and/ or CBD diameter wider than $2 \mathrm{~mm}$ in infancy, greater than 4 $\mathrm{mm}$ in childhood, and greater than $7 \mathrm{~mm}$ after adolescence were abnormal. However, the differentiation between choledochal malformation and variation within the normal limit is still difficult. 11,12

We had evaluated sonographically 162 children who met the Siegel's criteria for biliary tract dilatation. In our 18 years study, all cases of intrahepatic biliary tree dilatation and those with both intra- and extrahepatic duct dilatations were anomalous. However, in cases of extrahepatic biliary tract dilatation, $73 \%$ of patients with extrahepatic biliary dilatation had biliary anomalies. Thirty one children who had no clinical symptoms / signs as well as normal laboratory data during the follow-up period were thought to be normal variants. The mean diameters of them were $4.4 \pm 1.2 \mathrm{~mm} .{ }^{13}$

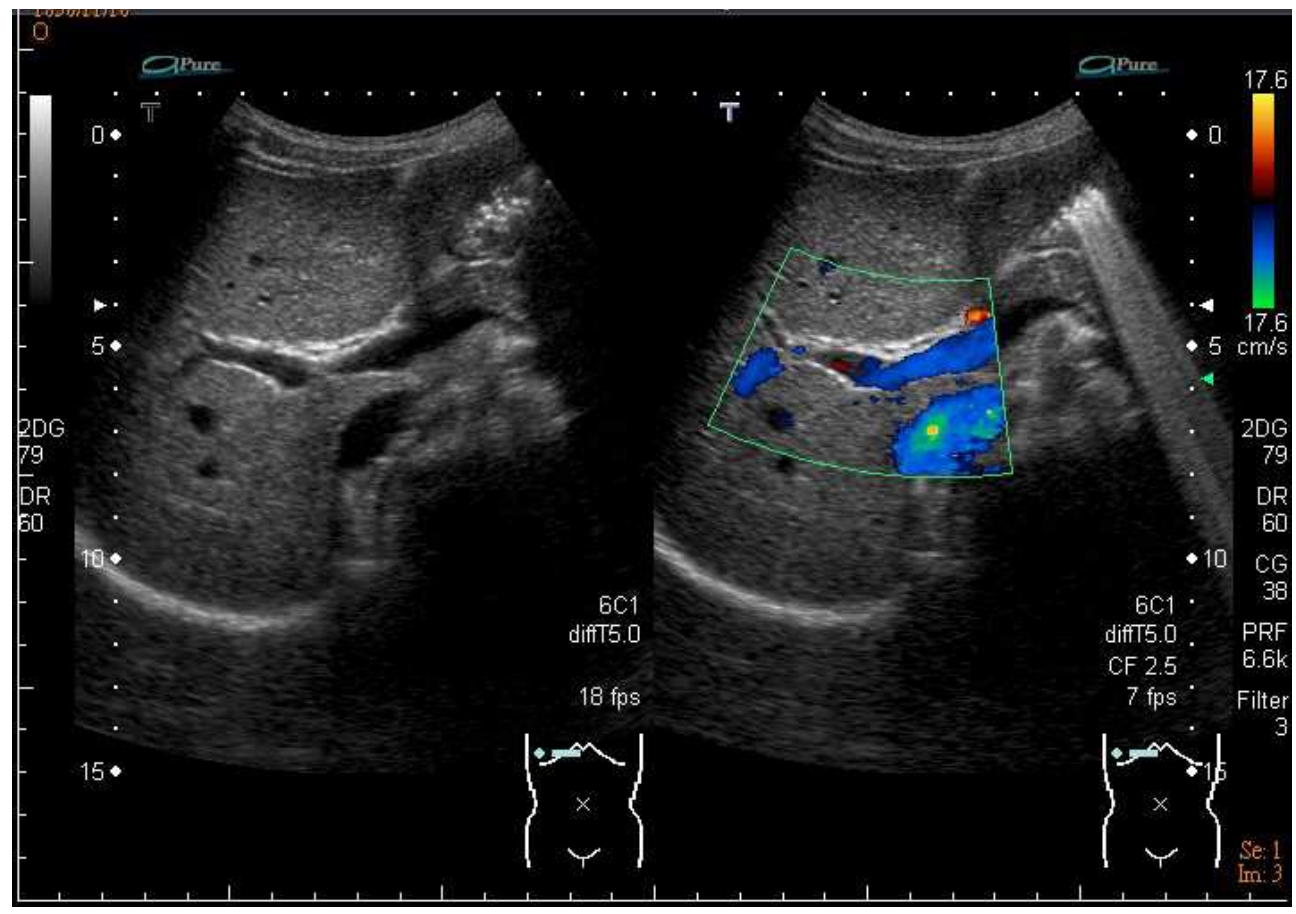

Fig. 3. Normal presentation of CBD Left: The CBD lies just anterior to the portal vein in porta hepatis and three echogenic lines will be seen. The first line closest to the probe will be the anterior wall of the CBD. The second line is the shared wall of the CBD and portal vein. And the third line is the posterior wall of the portal vein. Measurement of the caliper of CBD is usually done between the interior margin of the anterior and the posterior wall. Right: The CBD and portal vein can be easily differentiated by color Doppler. The portal vein will demonstrate flow and the CBD will not. (CBD: common bile duct) 


\section{Differential diagnosis of biliary dilatation in children}

Anomalous biliary tract dilatation, also namely biliary cysts, may be congenital or acquired. Most congenital lesions are found in the common bile duct, thus referred as choledochal cyst (CC). The anatomic classification of CC most commonly used was defined by Todani who divided CC into 5 types. ${ }^{14,16}$ The most common type (Type I) is a congenital cystic dilatation of the common bile duct without associated intrahepatic ductal dilatation (Fig. 4 \& 5). Type II is a diverticular malformation of the common bile duct, and Type III is a choledochocele associated with an ampullary obstruction. The Type IV malformation has multiple cysts of the intrahepatic or extrahepatic ducts, or both (Fig. 6). Type V has single or multiple intrahepatic cysts (Fig. 7).

In our study,,$^{13}$ excluding cases associated with biliary atresia, the accuracy of diagnosing choledochal cysts in extrahepatic biliary tract dilatation was $71 \%$ and $97 \%$ using cutoffs of 7 $\mathrm{mm}$ and $10 \mathrm{~mm}$ as the minimum diameter respectively.

We also reported 158 pediatric patients with biliary cysts seen between June 1981 and July 2004. ${ }^{17}$ Patients were divided into three groups: biliary atresia-associated biliary cyst (BABC), non-biliary atresia-associated choledochal cyst (NBACC) in infancy, and late NBACC ( $>1$ year of age). The mean diameter in BABC $(7.9 \pm 1.5 \mathrm{~mm})$ was significantly less than that in infantile NBACC $(16.0 \pm 3.7 \mathrm{~mm}, p<0.001)$ and late NBACC $(21.5 \pm 5.6 \mathrm{~mm}, p<$ $0.001)$. In NBACC, older age at diagnosis was associated with greater cyst diameter $(r=0.7$, $p<0.001)$.

BABC had been reported and had names synonymously as biliary duct dilatation with biliary atresia (BDBA), ${ }^{13}$ choledochal cyst associated with extrahepatic biliary atresia (CCBA), 18 and type I cyst of BA.19 A survey by the American Academy of Pediatric Surgery Section found that $13 \%$ of patients with cystic dilatation of the CBD had extrahepatic biliary atresia. ${ }^{20}$ In our study, there was a higher incidence that BABC accounted for $36.2 \%$ of the infantile biliary cysts. ${ }^{17}$

The type V CC was also termed Caroli disease. ${ }^{14,16}$ It involves dilatation of one or more segments of the intrahepatic ducts. Typically the intrahepatic ducts show marked saccular enlargement with communication between the cysts under sonography (Fig. 7). Caroli disease may be one part of ADPKD (Autosomal Dominant Polycystic Kidney Disease) or ARPKD (Autosomal Recessive Polycystic Kidney Disease) if intrahepatic dilatation located peripherally in the liver, namely type II Caroli disease. ${ }^{21}$ It can be differentiated from autosomal dominant polycystic liver disease which showed isolated intrahepatic cysts with no tubular connections between them. ${ }^{22,23}$

Several reports described that anomaly of pancreatic fusion ${ }^{24,25}$ or pancreatic heterotopias ${ }^{26}$ might cause congenital biliary dilatation.

Acquired cases usually appear as fusiform dilatations, which can be seen in those with tumors, lithiasis, and inflammation of the biliary tract (Fig. 8). External compression due to vascular malformation of the portal vein may also cause biliary tract dilatation. Tumor of biliary tract is extremely uncommon in children. Sludge and stone may be seen in those with hemolytic disease such as congenital spherocytosis, prolonged fasting, medications and total parenteral nutrition use. Cholangitis may induce biliary dilatation (BD) and mimic choledochal cyst. ${ }^{17}$ Other conditions have been reported to be related to $\mathrm{BD}$, including 


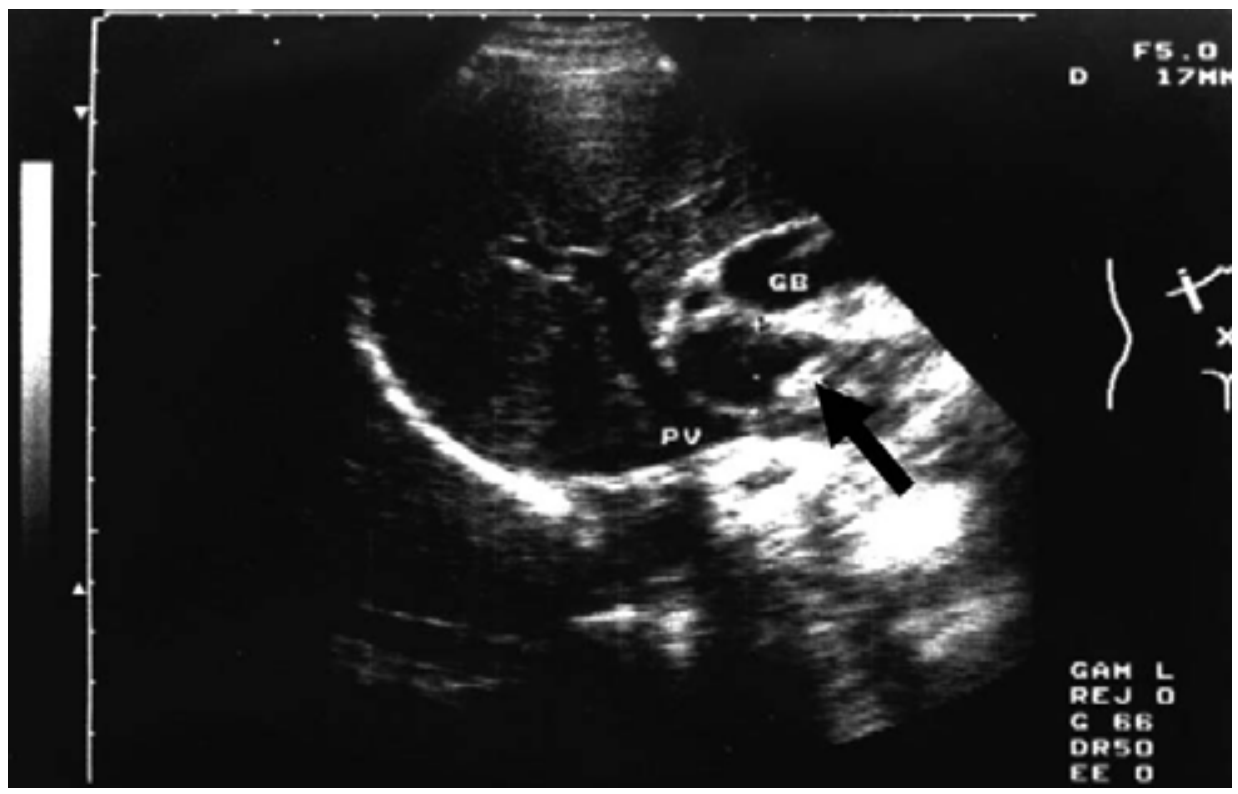

Fig. 4. Choledochal cyst Type Ia: cystic dilatation in the common bile duct with stone formation (arrow). PV = portal vein, GB = gallbladder. (From Lee HC: JMed Ultrasound 2007;15(3):191-196.)

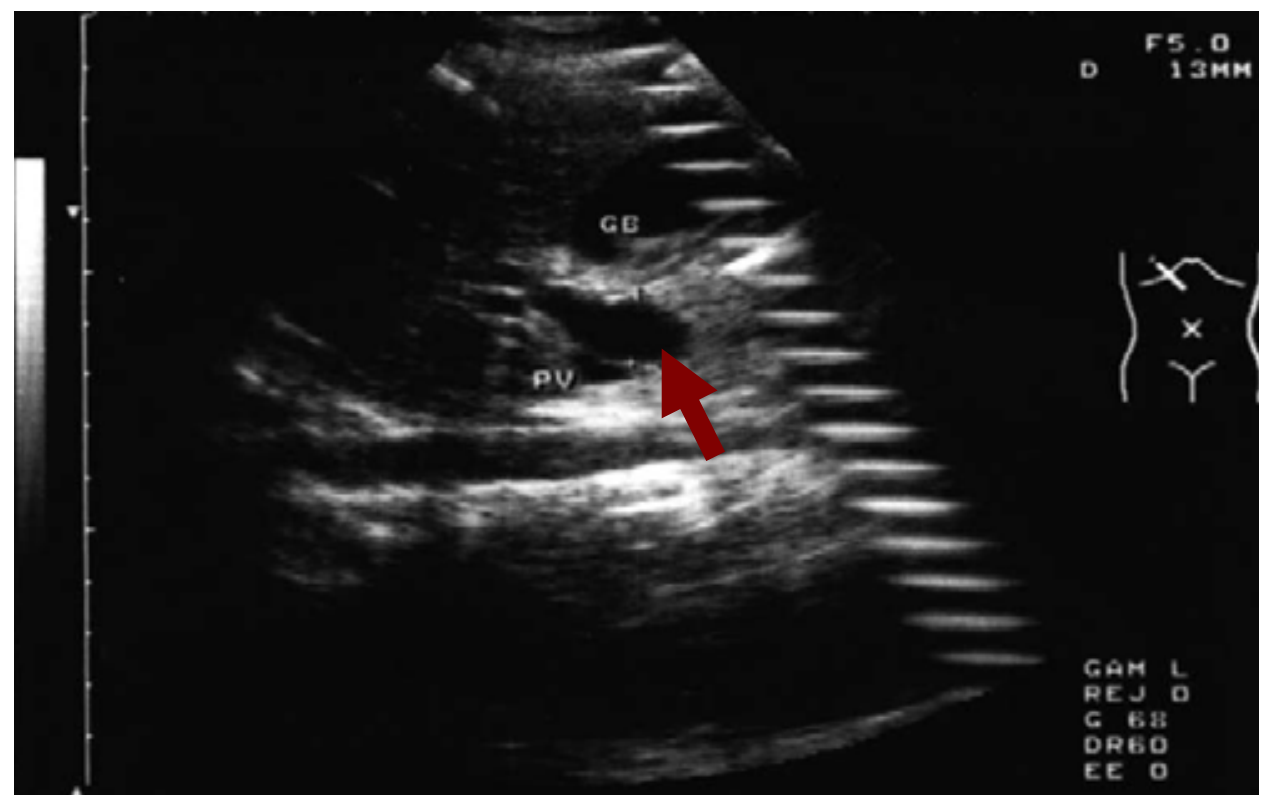

Fig. 5. Choledochal cyst Type Ic: a fusiform dilatation (arrow) in the common bile duct. PV = portal vein; GB = gallbladder. (From Lee HC: JMed Ultrasound 2007;15(3):191-196.) 
pancreatitis, gastrointestinal graft-versus-host disease, infections other than intra-abdominal sites, neonatal sepsis. ${ }^{27}$

Some sonographic findings may be mistaken as biliary tract dilatation, such as an elongation or folding of gallbladder neck, a dilated main hepatic artery anterior to the main portal vein, and a marked concentric, hypoechoic thickening of the walls of the CBD. However, a dilated CBD may be mistaken as normal-sized, such as a partially obscured dilated CBD by sludge or blood clot with only the residual lumen visualized. ${ }^{23}$ Careful and thorough examination to explore the lesions and the association with the surrounding structures should be undertaken. Looking for any special characteristic findings may help to avoid misdiagnosis.

Under sonography, a thin walled cystic or fusiform mass can be seen in the right upper quadrant of abdomen at subhepatic area or porta hepatis. The gall bladder must be visualized separately to make a diagnosis of choledochal cyst. The bile duct(s) can be seen communicating to the lesion. 28 The lesion has been described "tear drop" in shape with a sharp proximal end connected to the biliary tree. Stasis of bile may result in sludge or stone within the lesion. Septa are seldom found.

Any cystic lesions which are seen in the right upper quadrant sonographically must be differentiated. These include enteric duplication cyst, especially duodenal origin, hepatic cyst, pancreatic pseudocyst, mesenteric or omental cyst, renal cyst, and aneurysm of vessel at porta hepatis etc.

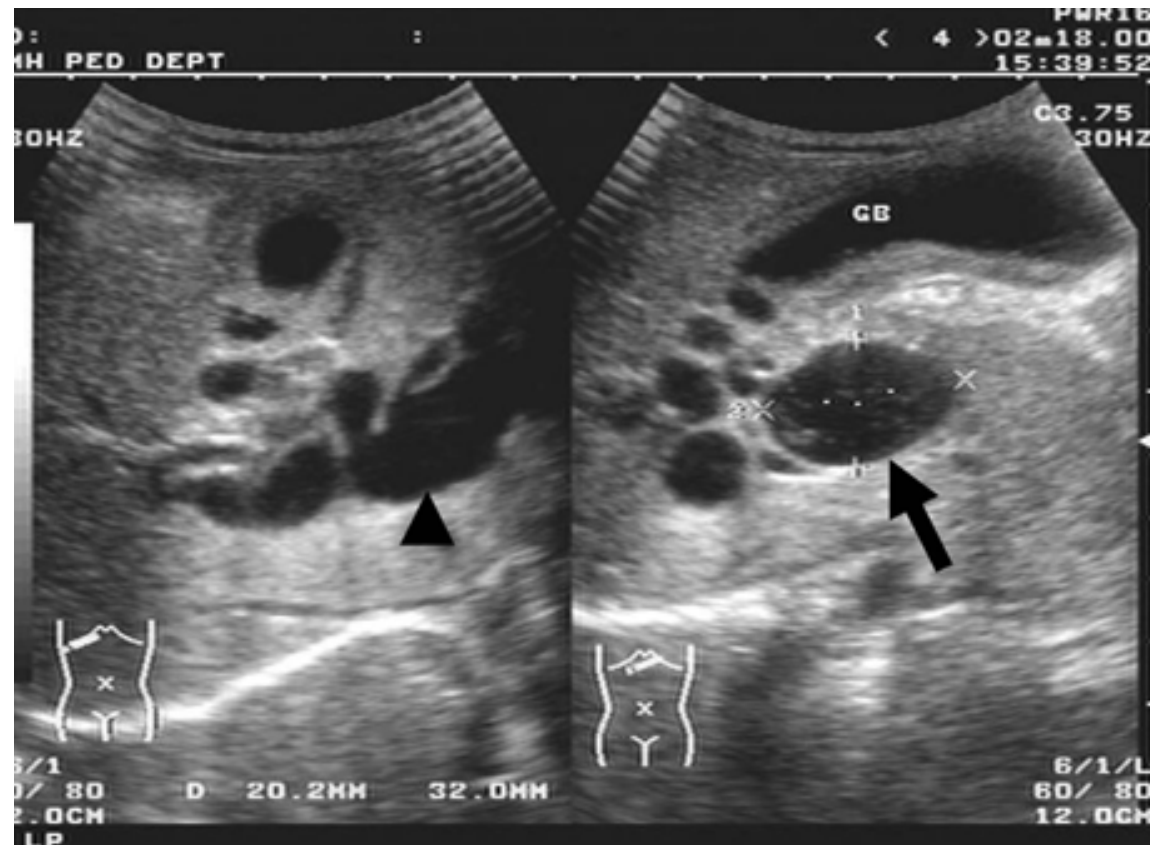

Fig. 6. Choledochal cyst Type IVa: a common bile duct cyst (arrow) with intrahepatic duct dilatation (arrowhead). GB=gallbladder. (From Lee HC: JMed Ultrasound 2007;15(3):191-196.) 


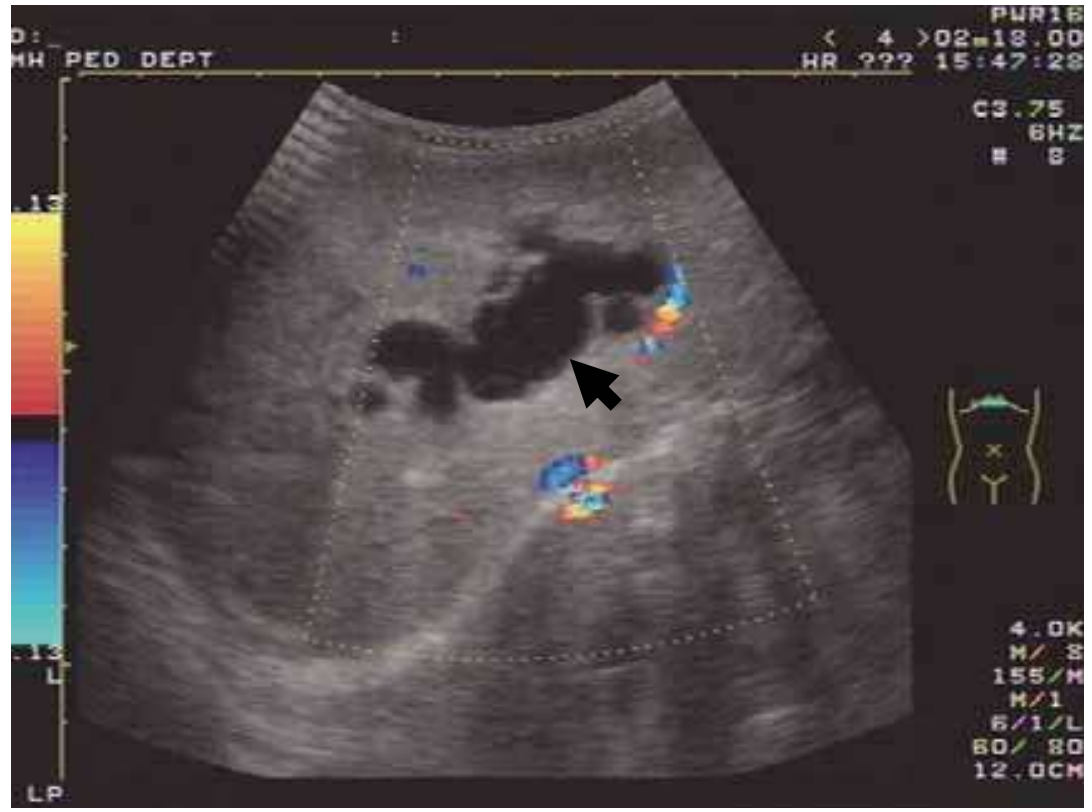

Fig. 7. Choledochal cyst Type V: saccular dilatation of the intrahepatic ducts (arrow). (From Lee HC: JMed Ultrasound 2007;15(3):191-196.)

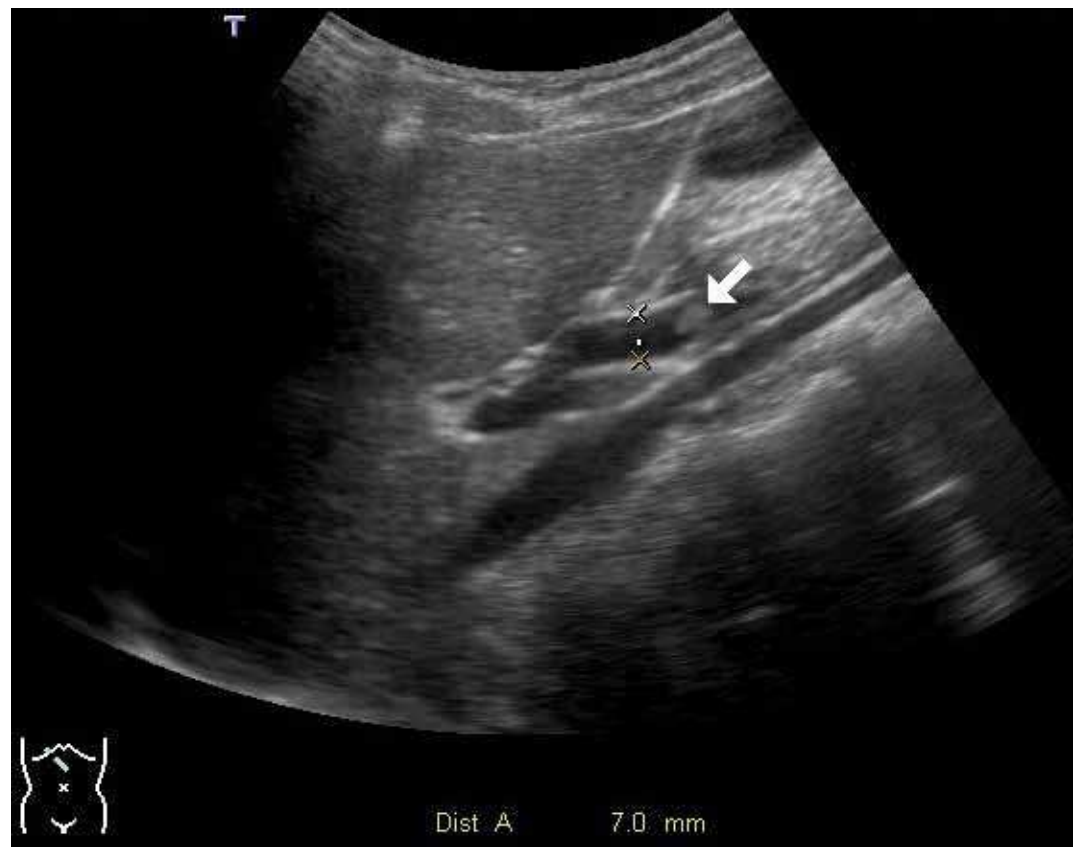

Fig. 8. Dilated common bile duct (7.0mm) with a stone (arrow) and acoustic shadow 


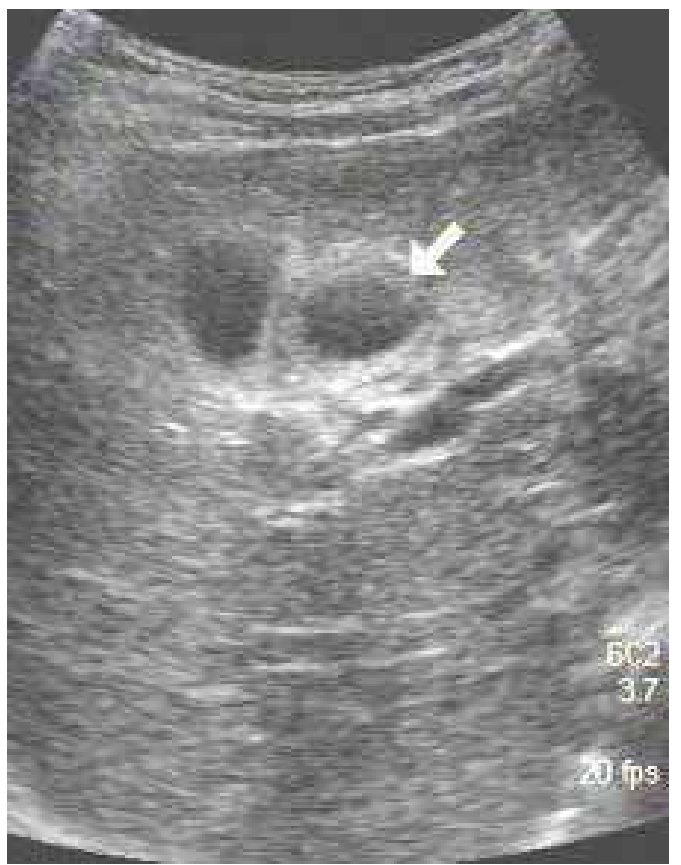

Fig. 9. A duodenal duplication cyst nearby gall bladder with the appearance of "rim sign" (arrow)

Enteric duplication cysts are mostly found in ileum and stomach. ${ }^{29}$ Several reports described duplication cyst originated from duodenum. ${ }^{30}$ Abdominal pain and intestinal obstruction are the most common clinical manifestations. ${ }^{31,32}$ Duodenal duplication cysts frequently associate with pancreatitis. ${ }^{30}$ Enteric duplication cysts consist of enteric wall in structure..$^{29}$ Mucosa and muscular layer of enteric duplication cysts give raise to an inner echogenic rim and an outer hypoechoic rim respectively when they are examined by sonography. The appearance is recognized as "rim sign" (Fig. 9) which is identified in the dependent portion of the cyst. 31

Congenital hepatic cysts (Fig. 10) are rare and usually are found incidentally. Most hepatic cysts located under anterior surface of the liver. They are usually anechoic with acoustic enhancement noted under sonography. They may show internal echo due to hemorrhage or infection, septa etc. Viewing the lesion through various scanning windows and angles helps differentiate it from choledochal cyst.

Mesenteric or omental cyst, now known as cystic lymphatic malformations, arises from non-communicating ectopic lymphatic structures in the abdomen. On ultrasound, the lesion presents as a thin wall cyst with multiple thin septa inside.33-35 Usually, mesenteric or omental cyst is large in size and may mimic ascites, so called "pseudo-ascites" ${ }^{36}$ Clinically, abdominal distension with or without a palpable mass is the most frequent presentation. 36 Small cyst may occur less commonly. The content of the cyst may be anechoic, or shows internal echo from hemorrhage, debris, chylous fluid or infection. ${ }^{34,35}$ Progressive 


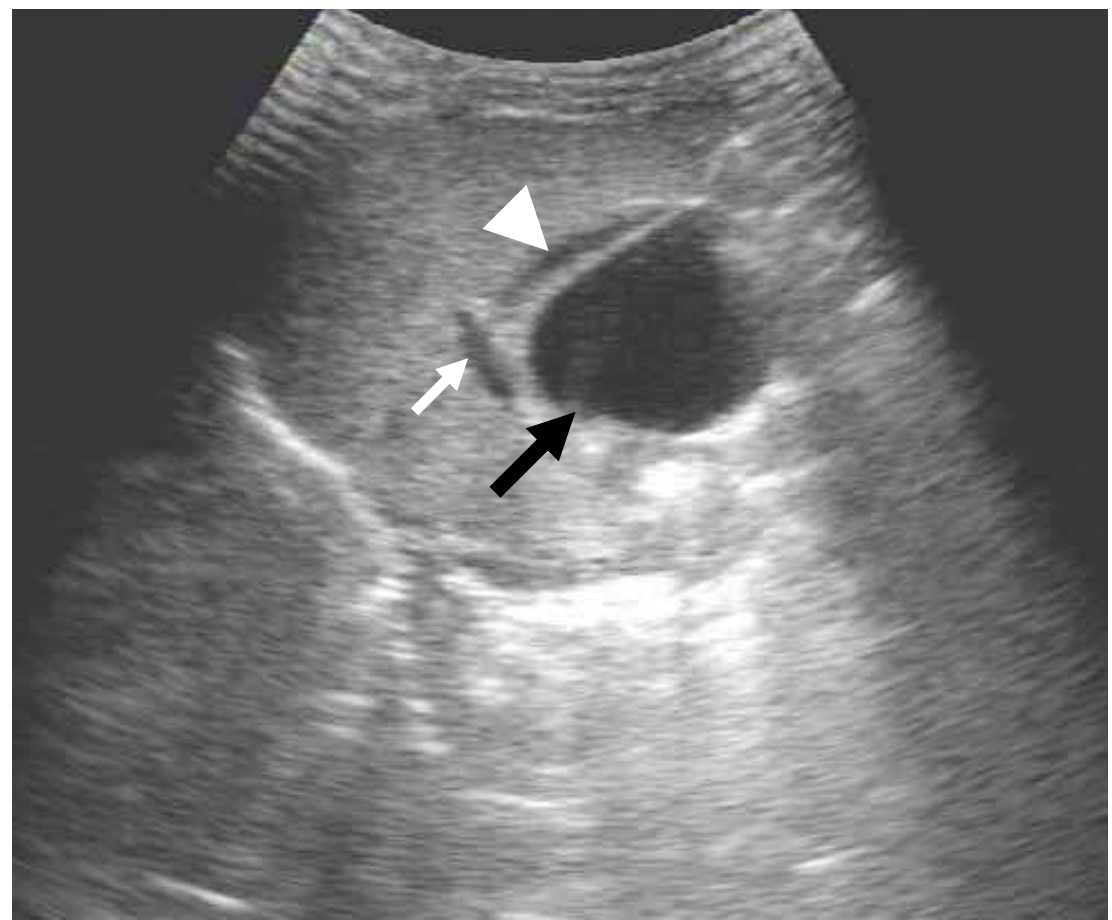

Fig. 10. A cystic mass (black arrow) at the porta hepatis compressing gall bladder (white arrow head) and portal vein (white arrow). Further study demonstrated the lesion to be a hepatic cyst

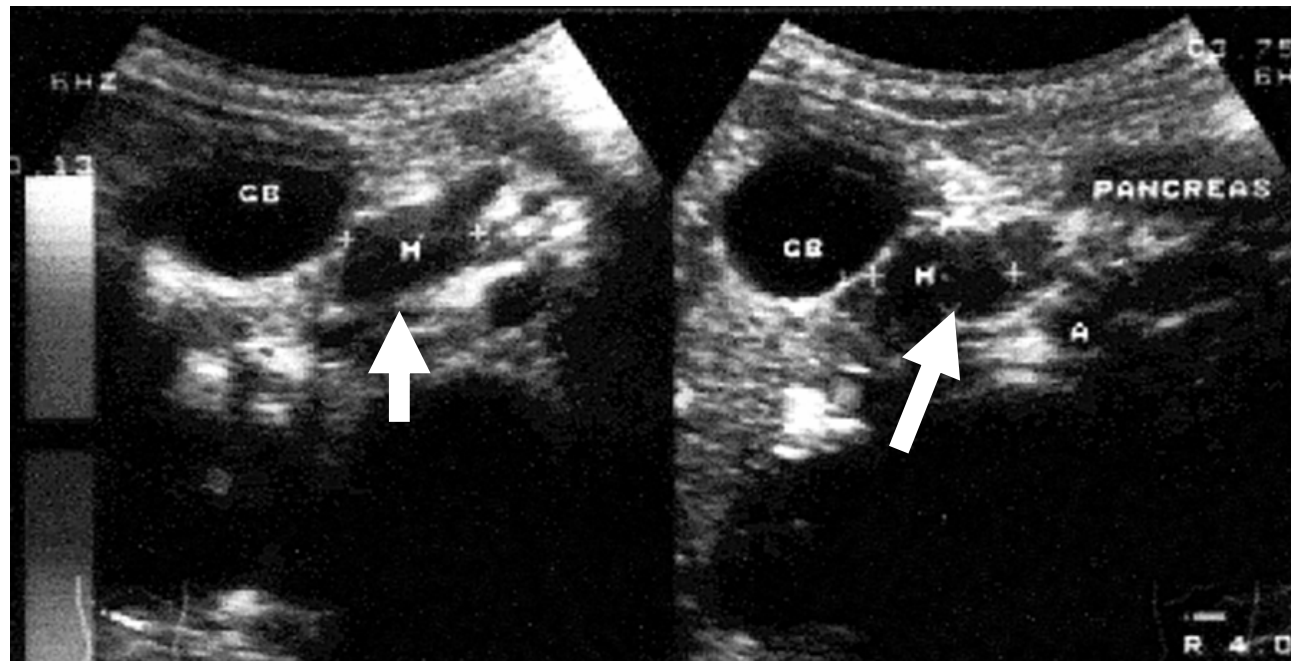

Fig. 11. A pseudocyst of pancreas (M, arrow) between the gallbladder (GB) and pancreas at the epigastrium 5 days after blunt abdominal injury. A: aorta 
enlargement, increase in fluid echogenicity, thickening of wall and septa and multiplication of septa may be seen by sequential sonography. ${ }^{34}$

Two-thirds of childhood pancreatic pseudocysts (Fig. 11) arise from the body or tail of the pancreas, mostly unilocular. ${ }^{37}$ Most of them are secondary to pancreatitis or blunt abdominal trauma. Pseudocyst is associated to the pancreas. The borders are usually echogenic and thicker than that of simple cyst.

Vascular malformations, though uncommon, simulate cystic lesions at the porta hepatis, may be mistaken as choledochal cyst. These include portal vein aneurysm (Fig. 12) and hepatic artery aneurysm. Most of the lesions are found incidentally when having a sonographic examination and appear as an anechoic fusiform or saccular structure. Sometimes these lesions may contain thrombus inside and give an echogenic image. These lesions can be distinguished readily by Doppler technique which demonstrates blood flow inside the cystic mass. ${ }^{38,39}$

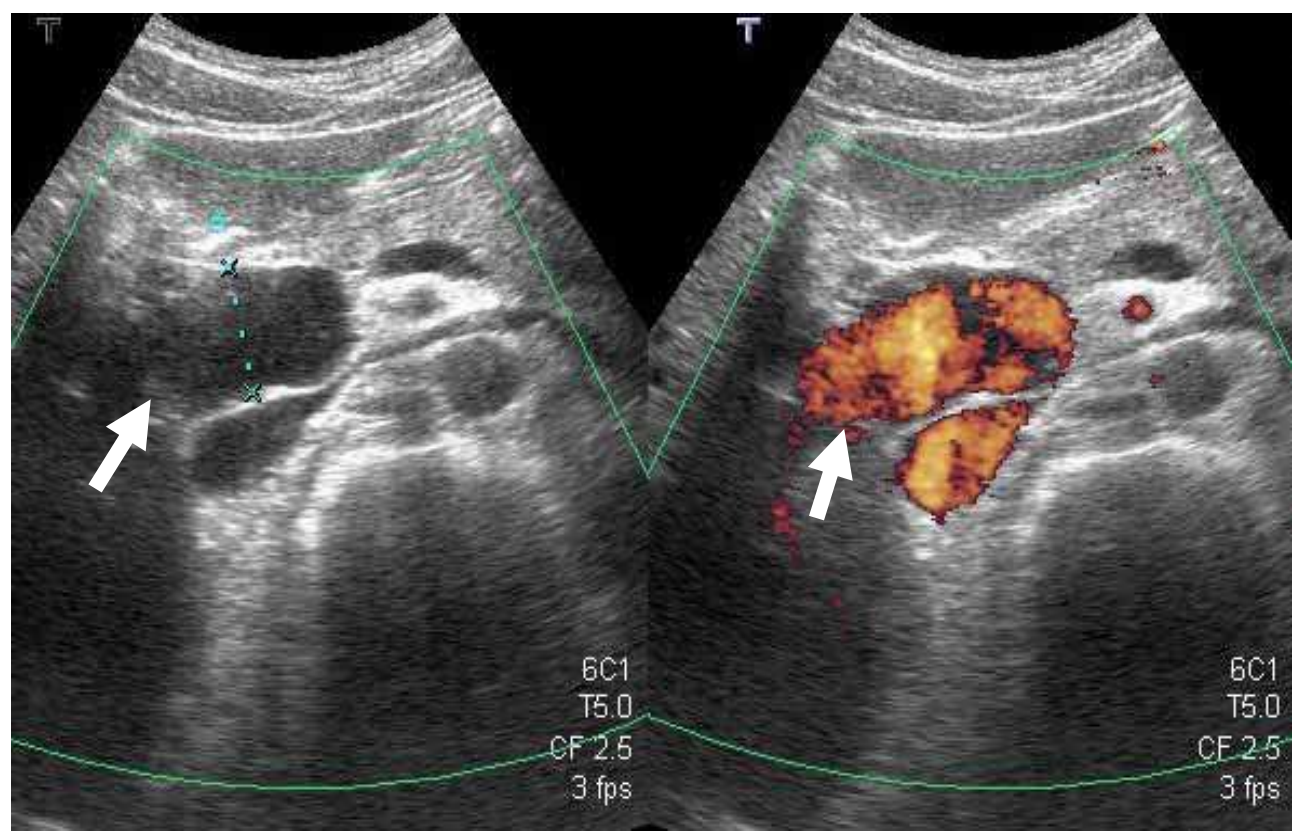

Fig. 12. A large cystic mass (arrow) at the porta hepatis with blood flow shown in the lesion (R't). Further imaging study revealed portal vein aneurysm

\section{References}

[1] Hernanz-Schulman M, Ambrosino MM, Freeman PC, et al: Common bile duct in children: Sonographic dimensions. Radiology 1995; 195:193.

[2] Wolson AH. Ultrasound measurements of the gallbladder. In: Goldberg BB, Kurtz AB, editors. Atlas of ultrasound measurements. Chicago: Year Book Publishers, Inc.; 1990. p.108-12. 
[3] R. A. L. Bissett, A. N. Khan: Differential Diagnosis in Abdominal Ultrasound, 3/ e; 2002

[4] Marilyn J. Siegel, Jaundice in Infants and Children. Ultrasound Clin 1: 2006;1:431-441.

[5] Akhan O, Demirkazik FB, Özmen MN, et al: Choledochal cysts: Ultrasonographic findings and correlation with other imaging modalities. Abdom Imaging 1994;19:243.

[6] Sringer MD, Dhaw an A, Davenport M, et al: Choledochal cysts: Lessons from a 20 year experience. Arch Dis Child 1995;73:528.

[7] Young W, Blane C, White SJ, et al: Congenital biliary dilatation: A spectrum of disease detailed by ultrasound. Br JRadiol 1990;63:333.

[8] Carroll BA, Oppenheimer DA, Muller HH. High-frequency real-time ultrasound of the neonatal biliary system. Radiology 1982;145:437-40.

[9] E. Fitzpatrick, R. Jardine, P. Farrant, et al. Predictive value of bile duct dimensions measured by ultrasound in neonates presenting with cholestasis, $J$ Pediatr Gastroenterol Nutr 2010;51:55-60.

[10] Siegel MJ. Liver and biliary tract. In: Siegel MJ, ed. Pediatric Sonography. New York: Raven Press, 1995:171.

[11] Grosfeld JL, Rescorla FJ, Skinner MA, et al. The spectrum of biliary tract disorders in infants and children. Experience with 300 cases. Arch Surg 1994;129:513-8.

[12] Lee SS, Min PC, Kim GS, et al. Choledochal cyst. A report of nine cases and review of the literature. Arch Surg 1969;99:19-28.

[13] Lee HC, Yeung CY, Chang PY, et al. Dilatation of the biliary tree in children: sonographic diagnosis and its clinical significance. eburnal of Ultrasound in Medicine. 2000;19:177-182.

[14] Todani T, Watanabe Y, Narusue M, Tabuchi K, Okajima K. Congenital bile duct cysts: Classification, operative procedures, and review of thirty-seven cases including cancer arising from choledochal cyst. American eburnal of Surgery. 1977;134(2):263269.

[15] Todani T, Narusue M, Watanabe Y, Tabuchi K, Okajima K. Management of congenital choledochal cyst with intrahepatic involvement. Ann Surg. 1978;187(3):272-280.

[16] Crittenden SL, McKinley MJ. Choledochal cyst--clinical features and classification. American eburnal of Gastroenterology. Aug 1985;80(8):643-647.

[17] Lee HC, Yeung CY, Fang SB, Jiang CB, Sheu JC, Wang NL. Biliary Cysts in Children Long-term Follow-up in Taiwan. eburnal of the Formosan Medical Association. 2006;105(2):118-124.

[18] Kim WS, Kim IO, Yeon KM, Park KW, Seo JK, Kim CJ. Choledochal cyst with or without biliary atresia in neonates and young infants: US differentiation. Radiology. 1998;209(2):465-469.

[19] Tsuchida Y, Kawarasaki H, Iwanaka T, Uchida H, Nakanishi H, Uno K. Antenatal diagnosis of biliary atresia (type I cyst) at 19 weeks' gestation: differential diagnosis and etiologic implications. eburnal of Pediatric Surgery. May 1995;30(5):697-699.

[20] Bancroft JD, Bucuvalas JC, Ryckman FC, Dudgeon DL, Saunders RC, Schwarz KB. Antenatal diagnosis of choledochal cyst. eburnal of Pediatric Gastroenterology \& Nutrition. Feb 1994;18(2):142-145. 
[21] Nakanuma Y, Terada T, Ohta G, Kurachi M, Matsubara F. Caroli's disease in congenital hepatic fibrosis and infantile polycystic disease. Liver. Dec 1982;2(4):346-354.

[22] Rosenthal SJ, Cox GG, Wetzel LH, Batnitzky S. Pitfalls and differential diagnosis in biliary sonography. RadioGraphics. 1990;10:285-311.

[23] Parulekar SG. Transabdominal Sonography of Bile Ducts. Ultrasound Quarterly. 2002;18(3):187-202.

[24] Tadokoro H, Suyama M, Kubokawa Y, Sai JK. Persistence of the Left Part of the Ventral Pancreas May Cause Congenital Biliary Dilatation. Pancreas. 2003;27(1):47-51.

[25] Nomura T, Shirai Y, Wakai T, Yokoyama N, Sakata J, Hatakeyama K. Narrow portion of the terminal choledochus is a cause of upstream biliary dilatation in patients with anomalous union of the pancreatic and biliary ducts. World cburnal of Gastroenterology. 2005;11(41):6503-6507.

[26] Kattepura S, Nanjegowda NB, Babu MK, Das K. Macroscopic pancreatic heterotopia on a congenital biliary dilatation. Pediatric Surgery International. 2010;26:847849.

[27] Shaoul R, Sukhotnik I, Toubi A. Neonatal sepsis presenting as a choledochal cyst. Acta Paediatrica. 2008;97:246-249.

[28] Kim OH, Chung HJ, Choi BG. Imaging of the choledochal cyst. RadioGraphics. 1995;15:69-88.

[29] Swischuk L. Alimentary tract. In: Swischuk L, ed. Imaging of the Newborn, Infant and Young Child. 4 ed. Baltimore: William and Wilkins; 1997:426.

[30] Chen J, Lee HC, Yeung CY, Chan WT, Jiang CB, Sheu JC. Meta-analysis: the clinical features of the duodenal duplication cyst. eburnal of Pediatric Surgery. 2010;45(8):1598-1606.

[31] Pinter AB, Schubert W, Szemledy F, Gobel P, Schafer J, Kustos G. Alimentary tract duplications in infants and children. European eburnal of Pediatric Surgery. Feb 1992;2(1):8-12.

[32] Segal SR, Sherman NH, Rosenberg HK, et al. Ultrasonographic features of gastrointestinal duplications. eburnal of Ultrasound in Medicine. Nov 1994;13(11):863870.

[33] Chateil $\mathbb{F}$, Brun M, Vergnes P, Andrieu de Lewis P, Perel Y, Diard F. Abdominal cystic lymphangiomas in children: presurgical evaluation with imaging. European eburnal of Pediatric Surgery. Feb 2002;12(1):13-18.

[34] Konen O, Rathaus V, Dlugy E, et al. Childhood abdominal cystic lymphangioma. Pediatric Radiology. Feb 2002;32(2):88-94.

[35] Ros PR, Olmsted WW, Moser RP, Jr., Dachman AH, Hjermstad BH, Sobin LH. Mesenteric and omental cysts: histologic classification with imaging correlation. Radiology. Aug 1987;164(2):327-332.

[36] Lin J, Fisher J, Caty M. Newborn intraabdominal cystic lymphatic malformations. Seminars in Pediatric Surgery. 2000;9:141-145.

[37] Wootton-Gorges SL, Thomas KB, Harned RK, Wu SR, Stein-Wexler R, D. Strain J. Giant cystic abdominal masses in children. Pediatric Radiology. 2005;35:1277-1288. 
[38] Lee HC, Yang YC, Shih SL, Chiang HJ. Aneurysmal dilatation of the portal vein. eburnal of Pediatric Gastroenterology \& Nutrition. Apr 1989;8(3):387-389.

[39] Athey PA, Sax SL, Lamki N, Cadavid G. Sonography in the diagnosis of hepatic artery aneurysms. American eburnal of Roentgenology. 1986;147:725-727. 


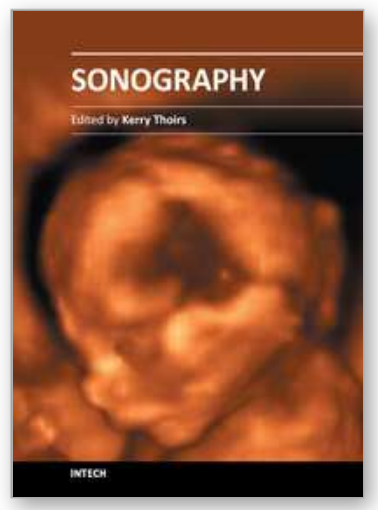

\author{
Sonography \\ Edited by Dr. Kerry Thoirs
}

ISBN 978-953-307-947-9

Hard cover, 346 pages

Publisher InTech

Published online 03, February, 2012

Published in print edition February, 2012

Medical sonography is a medical imaging modality used across many medical disciplines. Its use is growing, probably due to its relative low cost and easy accessibility. There are now many high quality ultrasound imaging systems available that are easily transportable, making it a diagnostic tool amenable for bedside and office scanning. This book includes applications of sonography that can be used across a number of medical disciplines including radiology, thoracic medicine, urology, rheumatology, obstetrics and fetal medicine and neurology. The book revisits established applications in medical sonography such as biliary, testicular and breast sonography and sonography in early pregnancy, and also outlines some interesting new and advanced applications of sonography.

\title{
How to reference
}

In order to correctly reference this scholarly work, feel free to copy and paste the following:

Hung-Chang Lee, Chuen-Bin Jiang, Wai-Tao Chan, Chun-Yan Yeung (2012). Sonogram of Biliary Dilatation in Children, Sonography, Dr. Kerry Thoirs (Ed.), ISBN: 978-953-307-947-9, InTech, Available from: http://www.intechopen.com/books/sonography/sonogram-of-biliary-dilatation-in-children

\section{INTECH}

open science | open minds

\section{InTech Europe}

University Campus STeP Ri Slavka Krautzeka 83/A 51000 Rijeka, Croatia Phone: +385 (51) 770447 Fax: +385 (51) 686166 www.intechopen.com

\section{InTech China}

Unit 405, Office Block, Hotel Equatorial Shanghai No.65, Yan An Road (West), Shanghai, 200040, China 中国上海市延安西路65号上海国际贵都大饭店办公楼 405 单元 Phone: +86-21-62489820

Fax: +86-21-62489821 
(C) 2012 The Author(s). Licensee IntechOpen. This is an open access article distributed under the terms of the Creative Commons Attribution 3.0 License, which permits unrestricted use, distribution, and reproduction in any medium, provided the original work is properly cited. 